\title{
Study the capabilities of RTK Multi GNSS under forest canopy in regions of Indonesia
}

\author{
Heri Andreas ${ }^{1, *}$, Hasanuddin Zainal Abidin ${ }^{1}$, Dina Anggreni Sarsito ${ }^{1}$ and Dhota Pradipta ${ }^{1}$ \\ ${ }^{1}$ Geodesy Research Division, Faculty of Earth Science and Technology, Institute of Technology Bandung, Indonesia
}

\begin{abstract}
For more than two decade, the position on the earth can be precisely determined "real-time" in the order of few centimeters by Real Time Kinematic (RTK) GNSS (Global Navigation Satellite Systems) Method. Nevertheless, few limitations are still recognized such as degradation of accuracy against limited satellite visibilities (e.g. heavy satellite obstructions from forest canopy). It usually takes time to resolve the ambiguities or even in many occasion resulted in failure. Fortunately since recent years to the future seems more satellite systems beside GPS and GLONASS are being launched such as BEIDOU, GALILEO, QZSS, etc. It means that more satellite will be existed above the sky. The term GNSS has changed into Multi GNSS. This Multi GNSS is theoretically adding the value to previous GNSS System like GPS; problems of limited satellite visibilities (e.g. under forest canopy) to the position accuracy perhaps will reduce. Within this paper we try to do study the capabilities of RTK Multi GNSS under forest canopy in Indonesia. We observed by RTK in the forest areas which have canopy of 40 to 90 percent. As conclusion we found improvement in positioning result of even area of very limited satellite visibilities.
\end{abstract}

\section{Introduction}

Back in the early 70 , the revolution in world scale positioning has begun as the satellite technology invented. Before that moment the best technique for worldwide positioning were using astronomical technique with their limitation of accuracy while after on the satellite base GNSS (Global Navigation Satellite System) technology has been played as remarkable tool for positioning and mapping with high accuracy can be achieved in the easiest way (Seeber [1], Abidin [2-3], Leick [4], Hofmann et. al [5]). In everywhere and in anytime worldwide when signals from the satellites GNSS (e.g. GPS and GLONASS) received by the receivers, in these cases the position in $3 \mathrm{D}$ or even $4 \mathrm{D}$ can be determined precisely and even with precision in the order of millimeter. Not to mention, the position can be also precisely determined "real-time" in the order of few centimeter by RTK (Real Time Kinematic) Method. The GNSS indeed become a revolution in positioning on the $20^{\text {th }}$ century. Nevertheless, few limitations are still recognized such as the capability of positioning under heavy satellite obstructions (e.g. in dense urban area, and in canopy area like forest), especially for the RTK method (figure 1). Obstruction will disturb the signal connection and produce cycle slip, and un-favor fixing the ambiguity (Leick [4], Mudita et.al [6]). As for the RTK, in many cases it would give autonomous result, float solution, hardy waiting for resolved ambiguity, and or in some cases given the possibility of fixing to the wrong integer. Not to mention if we set up longer baseline, therefore the degradation in accuracy will more significant. This is the new challenge to be solved, since many applications are dealing with situation of positioning under heavy satellite obstruction such as for forest boundary surveys, rural urban parcel measurements, in between high rise building measurements, etc. Theoretically the availability of more satellites, the existence of another phase signal, and or stronger signal may answer the limitation.

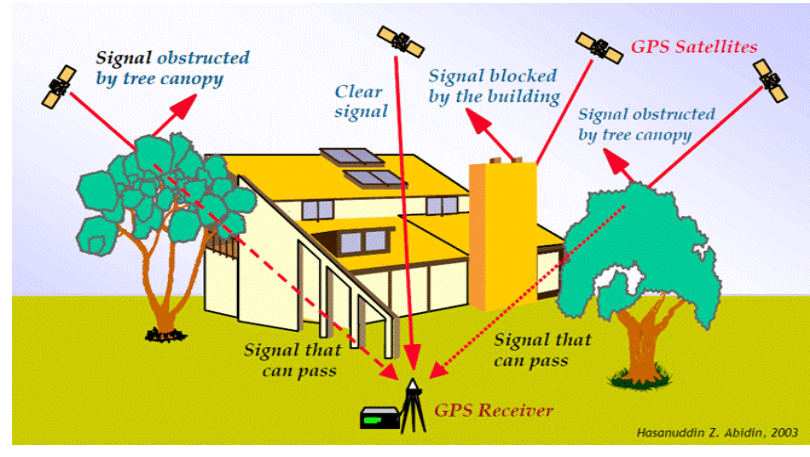

Fig. 1. Illustration of obstruction (e.g. tress canopy, building) and interference to GNSS signal

In the recent years, the GNSS BEIDOU or COMPASS has been launched by the China, the GALILEO by European Union, QZSS (Quasi Zenith Satellite System) by the Japan, and so on. This additional satellite system is theoretically adding the value to others GNSS System since more satellite can be observed (figure 2). With combination of geostationary and the moving satellites, it may improve the capability in

*Corresponding author: heriandreas49@gmail.com 
positioning, especially for the RTK method. Problems of satellite obstruction perhaps will reduced by the combination of GPS, GLONASS, BEIDOU, GALILEO and others. The better result on the position is also expected. The term of GNSS has changed into Multi GNSS. Within in this paper we try to do exercise on the capability of RTK Multi GNSS under forest canopy area where we have challenge for satellite signal observation. We observed by this RTK in National Forest Park in northern Bandung, and in forest area in Jambi Indonesia Province where 40 to even 90 percent of canopy existed. This paper will highlight if there are or aren't any improvements in positioning result, especially for the area as mentioned above when many user trend in using more RTK method.

Satellites - Skyplot

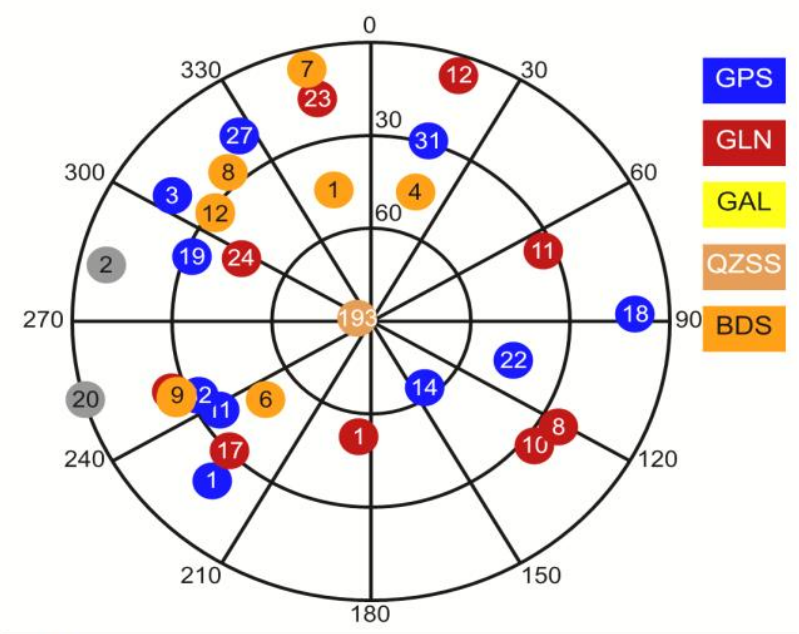

Fig.2. Constellation of Multi GNSS system (e.g. GPS, GLONASS, BEIDOU, GALILEO) allow us to observe more satellite

\section{Method}

As previously mention before era of Multi GNSS, degradation of precision of coordinate's position will likely to occur when we measure under heavy obstruction to the satellites like in the forest area. Troubles during measurement are typically existed such as takes time to resolve the ambiguities or even in many occasion resulted in failure. So, it is very interesting to see how multi GNSS can improve that precision and even accuracy under such situation. For the information, measuring boundary of forest (either between forest and forest with non-forest) is necessary for production, conservation, etc. So we try to do study.

We observe the boundary simulation of forest by RTK Multi GNSS in Forest Park northern Bandung and forest concession Jambi. We simulate line with several points. One line represent boundary between two forests while the other one is boundary between forest and nonforest (figure 3 ). In every simulation point we observe repeatedly 100 coordinates value to see the precision statistically for horizontal and vertical component.

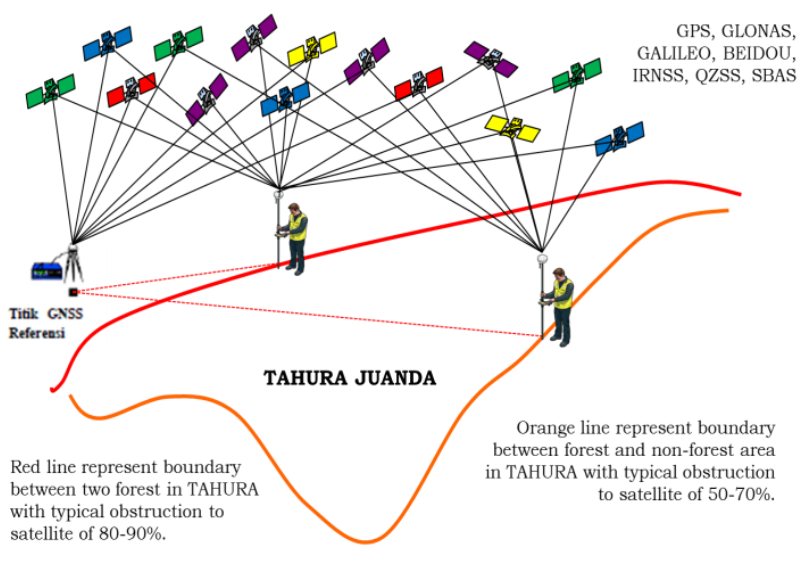

Fig.3. Illustration of measurements of simulation in the field. We measured boundary between two forests and the forest with non-forest area.

Further on we estimate the percentage of obstruction to the satellites as consequences from canopy in every measurement points. We grouped the points into 40 percent, 50, 60, 70, 80 and 90 percent of satellite signal obstruction. The estimation is simply by set up 15 degree of mask angle over 360 degree of horizon and clustered all quadrant of satellite until zenith. We see spatially the clear and the obstruction to the satellite and put them on percentage value.

Figure 4 show the illustration of satellite signal obstruction from tress canopy. With such obstruction theoretically less satellite will be observed and even chance to have cycle slip is higher. This limitation of number of satellite and many of cycle slip will be troubles for fixing the ambiguities and finally degrade the position precision and accuracy.

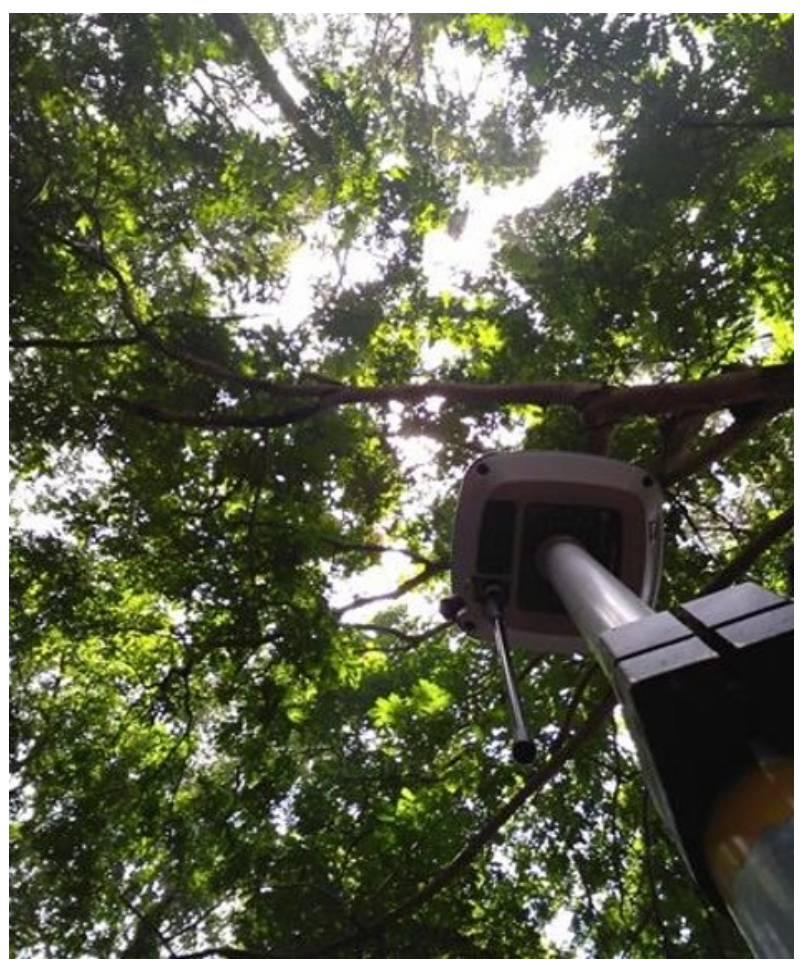

Fig.4. Illustration of satellite obstruction in the field due to forest canopy. The obstruction can be up to 90 percent. 
In order to do the measurements we use geodetic type Multi GNSS Channel System STONEX S800 and S10. These receivers can observe well the GPS, GLONASS, BEIDOU, GALILEIO, QZSS and others GNSS available. We may observe 20 to 30 satellites simultaneously in the sky with mask angle 15 degree. So far many vendors are busy to upgrade their receivers to become Multi GNSS Channel System.

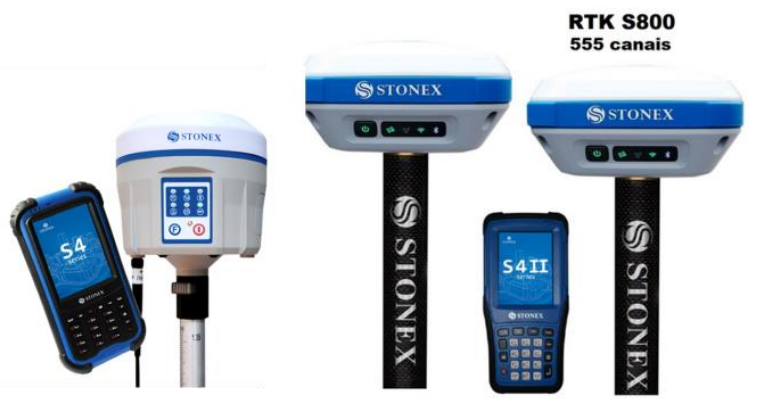

Fig.5. Geodetic multi-channel of multi GNSS STONEX S800 and S10 that are used for this research.

We set up base and rover with baseline length generally below 1 kilometer. The first reason is to make sure the correction of RTK from base to rover well received. With using only 0.5 Watt of radio communication we need to put closer the base and the rover, otherwise the radio signal might be lost. Shorter baseline will also reduce biases from atmospheric effect (e.g. Ionosphere and troposphere) and also reduce the orbital error. In this case we can focus more to the obstruction influence which relatively affect the ambiguity resolution. Off course study for the longer baseline is very interesting and even necessary as in many time it is not cost effective to put closer base.

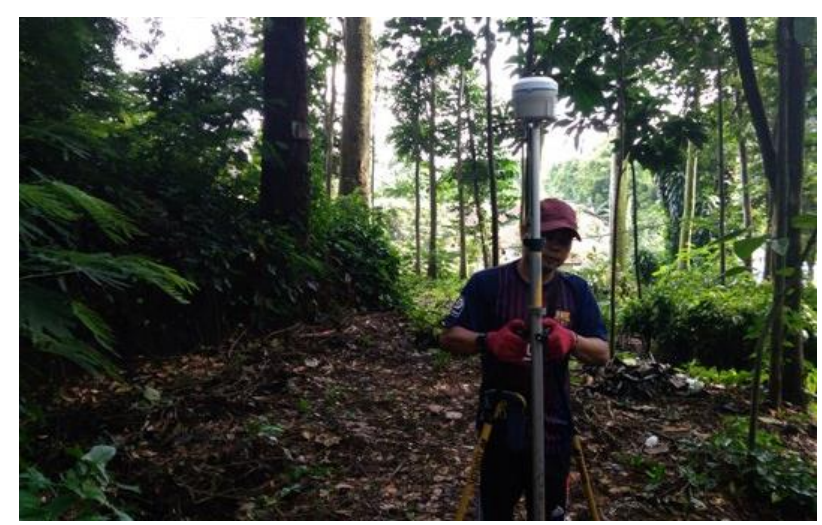

Fig.6. Documentation of RTK Multi GNSS in National Forest Park in northern of Bandung

Figures 6 show documentation of RTK Multi GNSS measurement in National Forest Park in northern of Bandung. The time of data acquisition in this area was in March 2018 while in forest concession Jambi was around March 2017. Both of data point's acquisition were processed together and also analyze together. As mentioned earlier we grouped the points into 40 percent, $50,60,70,80$ and 90 percent of satellite signal obstruction.

\section{Results}

Figure 7 to 10 show plotted of horizontal and vertical component from 100 repeated measurements in each group of points each represent 60 percent of satellite signal obstruction due to canopy, 70, 80 and 90 percent respectively. Few of outlier was removed. The existence of outlier was probably to the resolution of ambiguity to the wrong integer. As we now with many cycle slip and few only satellite recorded as in heavy obstruction, resolving ambiguity is not easy.

Result of 60 percent (figure 7) shows average horizontal precision of 1 centimeter and average vertical precision of 1 centimeter. Average time to fix ambiguity for 60 percent obstruction is 10 second with all ambiguities was fixed. Result of 70 percent (figure 8) shows average horizontal precision of 1 centimeter and average vertical precision of 2 centimeter. Average time to fix ambiguity for 70 percent obstruction is 10 second with all ambiguities was fixed. Result of 80 percent (figure 9) shows average horizontal precision of 3 centimeter and average vertical precision of 11 centimeter. Average time to fix ambiguity for 80 percent obstruction is 13 second with several ambiguities was remains float. Result of 90 percent (figure 10) shows average horizontal precision of 3 centimeter and average vertical precision of 8 centimeter. Average time to fix ambiguity for 90 percent obstruction is 2 minutes with more than a half of ambiguities were remains float.

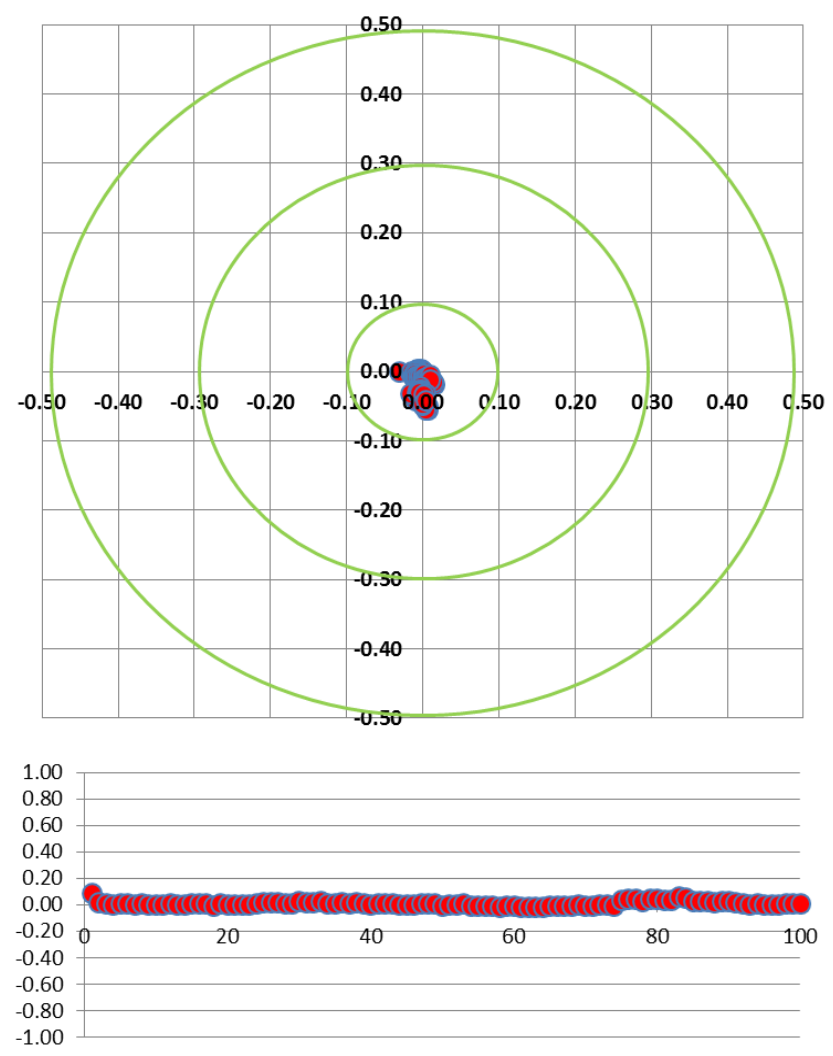

Fig.7. Plot of horizontal component and vertical component (all in meter). They figure out their precision of location with 60 percent of canopy obstruction to the satellite 

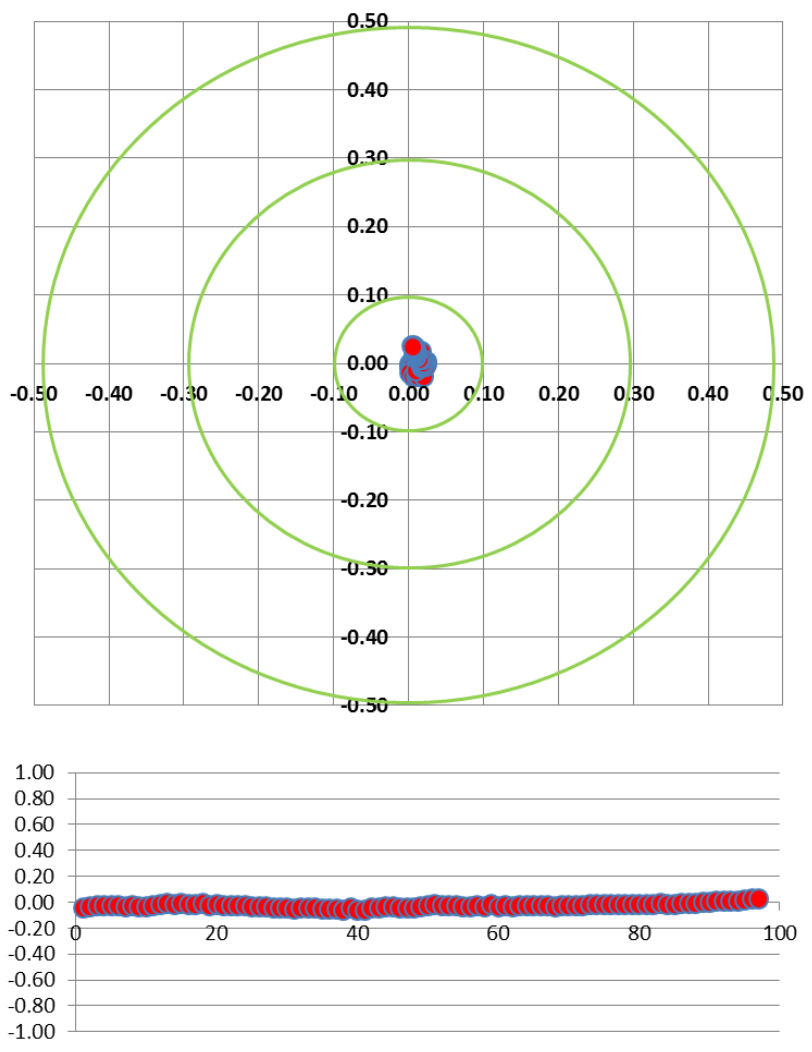

Fig.8. Plot of horizontal component and vertical component (all in meter). They figure out their precision of location with 70 percent of canopy obstruction to the satellite
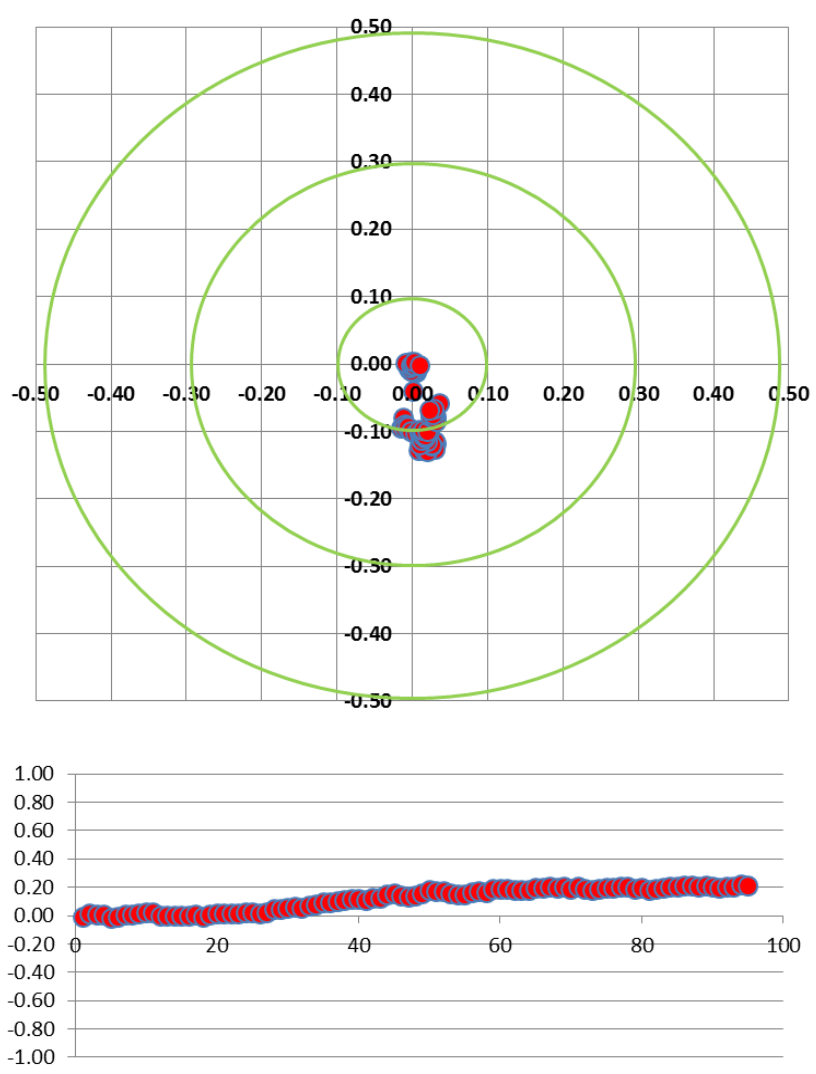

Fig.9. Plot of horizontal component and vertical component (all in meter). They figure out their precision of location with 80 percent of canopy obstruction to the satellite
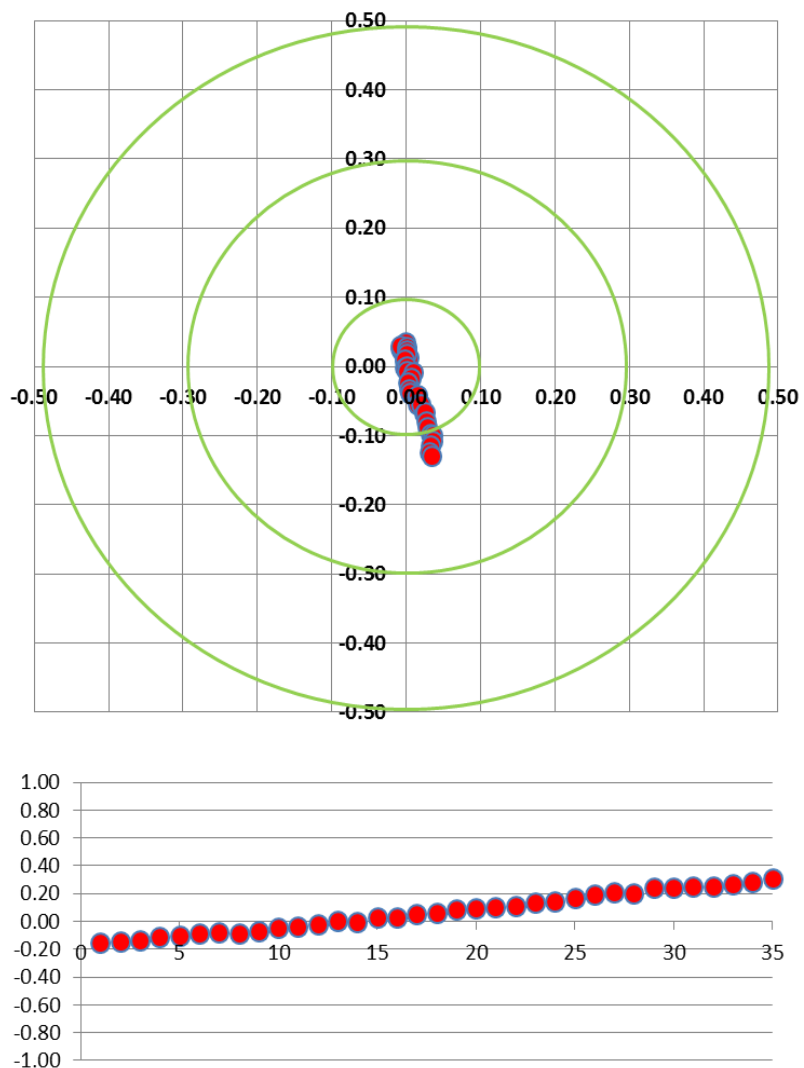

Fig.10. Plot of horizontal component and vertical component (all in meter). They figure out their precision of location with 90 percent of canopy obstruction to the satellite.

Table 1 summarize the average of horizontal and vertical precision of 100 times measurements and groups of the same typical obstruction to the satellite (e.g. 60 percent, 70,80 and 90 percent). Degradation of precision and longer time to fix the ambiguity is clearly seen when more obstruction to satellite existed. For 80 and 90 percent of obstruction, fixing ambiguity sometimes failed. We have record of several float solution for 80 percent obstruction and even more than a half data of float solution for 90 respectively.

Table 1. Summary of average horizontal and vertical precision for different obstruction to satellite visibilities.

\begin{tabular}{|c|c|c|c|c|}
\hline & $\begin{array}{l}\text { Obstruction } \\
\text { to satellite } \\
\text { visibilities } \\
\mathbf{6 0 \%}\end{array}$ & $\begin{array}{l}\text { Obstruction } \\
\text { to satellite } \\
\text { visibilities } \\
\mathbf{7 0 \%}\end{array}$ & $\begin{array}{l}\text { Obstruction } \\
\text { to satellite } \\
\text { visibilities } \\
\mathbf{8 0 \%}\end{array}$ & $\begin{array}{l}\text { Obstruction } \\
\text { to satellite } \\
\text { visibilities } \\
\mathbf{9 0 \%}\end{array}$ \\
\hline $\begin{array}{c}\text { Average } \\
\text { horizontal } \\
\text { precision }\end{array}$ & $0.01 \mathrm{~m}$ & $0.01 \mathrm{~m}$ & $0.03 \mathrm{~m}$ & $0.03 \mathrm{~m}$ \\
\hline $\begin{array}{c}\text { Average } \\
\text { Vertical } \\
\text { precision }\end{array}$ & $0.01 \mathrm{~m}$ & $0.02 \mathrm{~m}$ & $0.11 \mathrm{~m}$ & $0.08 \mathrm{~m}$ \\
\hline $\begin{array}{c}\text { Ambiguity } \\
\text { status }\end{array}$ & All Fix & All Fix & $\begin{array}{c}\text { Fix \& } \\
\text { Float }\end{array}$ & $\begin{array}{c}\text { Fix \& } \\
\text { Float }\end{array}$ \\
\hline $\begin{array}{c}\text { Time to } \\
\text { FIX } \\
\text { ambiguity }\end{array}$ & $10 \mathrm{sec}$ & $10 \mathrm{sec}$ & $30 \mathrm{sec}$ & $2 \mathrm{~min}$ \\
\hline $\begin{array}{c}\text { Baseline } \\
\text { length }\end{array}$ & $<1 \mathrm{~km}$ & $<1 \mathrm{~km}$ & $<1 \mathrm{~km}$ & $<1 \mathrm{~km}$ \\
\hline
\end{tabular}


Result of coordinate position from RTK Multi GNSS on forest area as studied is enough for boundary forest requirement. Indeed according to specification only sub meter accuracy is recommended for between forests and few decimeter recommended for forest and non-forest while from studied we can achieved better result of few centimeter of precision. Sub meter of accuracy generally requested also for administration boundaries such as province and districts.

Figure 11 show plotted of coordinates of measurements at National Forest Park northern of Bandung on Google Map. We noted that typical obstruction between forests is about 70-90 percent while typical for forest and non-forest is about 40-60 percent. Result of study is promising for forest boundary demarcation. To make sure the capabilities it is good to conduct study in more sample area. Perhaps each area has its own characteristic that is influence the result of measurements.

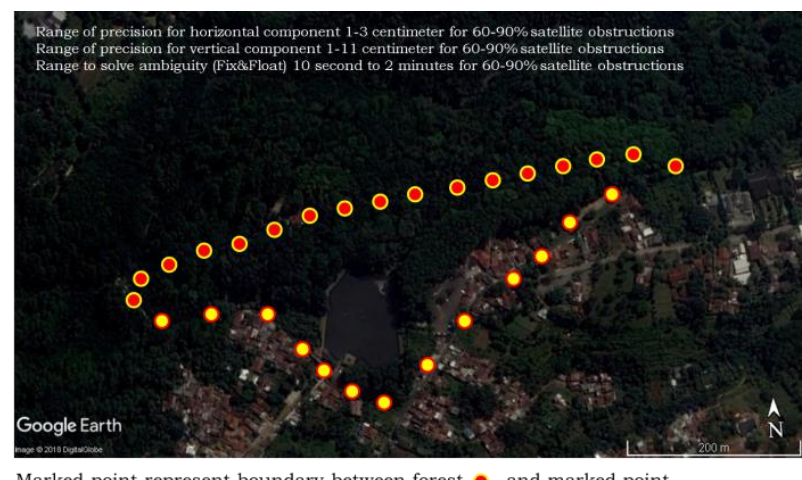

Marked point represent boundary between forest $\bullet$, and marked point represent boundary between forest and non-forest in JUANDA $O$

Fig.11. Plotted of results of measurements on the Google map. Result of measurements is promising for forest boundary demarcation.

\section{Discussions}

Problems for better result of coordinate's position on limited satellite visibilities or more obstruction to the satellite seem answered by Multi GNSS System. An easy reason is due to more satellite availability. As mentioned earlier with GPS, GLONAS, BEIDOU, GALILEIO, QZSS and others GNSS System available, 20 to 30 satellite can be measured simultaneously. Theoretically we need only 4 satellite to calculate position. Nevertheless the more is better. Another more specific reason why Multi GNSS System given better result on coordinate is the availability of geostationary satellites. As we know that several BEIDOU satellites is set up at geostationary orbit. QZSS is also typically a geostationary satellite with quasy move a bit along zenith. The existence of geostationary satellites will give more stability on the signal transmission and reduce the potency of cycle slip. In this case it would be easier on calculation of position especially when resolving the ambiguity.

On this study we still set up baseline below 1 kilometer and we only analyze precision component. Theoretically the longer baseline the more challenge on achieving good coordinate. Precision is not always accuracy while the accuracy is true indicator of good coordinates. So in the future we need to study longer baseline and take a look on accuracy instead precision only.

Indonesia has huge forest area (figure 12). It divided to conservation forest, peat land, production forest, society forest, etc. Definition on their boundary in this case is necessary. As mentioned earlier we need the boundary for management, production and for sure for conservation. We have degradation on forest area which is one factor is due to uncertainty in the boundary.

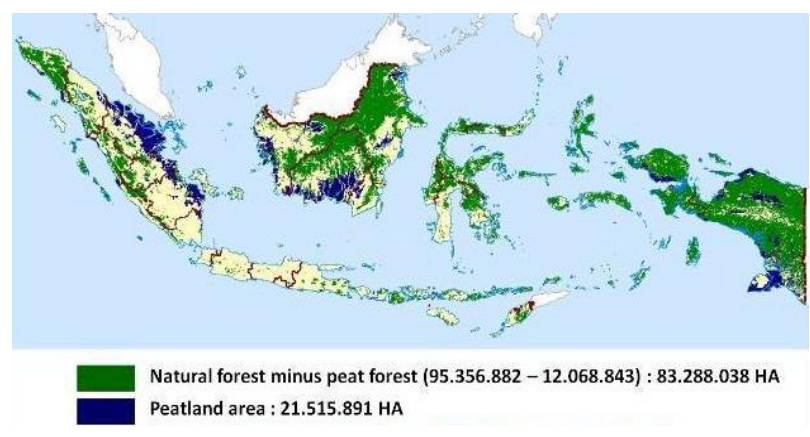

Fig.12. Map of Indonesia forest (Natural and Peat land)

Many methods and technologies have been applied for forest boundary demarcation. Firstly we use Theodolite and followed by Total Station. Several years ago we use GPS. The result of demarcation is not optimum yet. Using Total Station is time consuming while using GPS we have problem of satellite obstructions. The availability of RTK Multi GNSS again we stated it is quite promising for better forest boundary demarcation. Combination of CORS (Continuously Operating GNSS Reference Station) and RTPPP (Real Time Precise Point Positioning) is seems very interesting for further study.

\section{Conclusion}

Result of coordinate's position from RTK Multi GNSS on forest area as studied is enough for boundary forest requirement. This RTK Multi GNSS give better result on the coordinate position on limited satellite visibilities or more obstruction to the satellite since more satellite can be observed and there are several geostationer satellite which help more stability on the signal transmission and reduce the potency of cycle slip that are crucial parameters for deliver good coordinates position.

With such huge hectare of forest in Indonesia and others reason it makes forest boundary demarcation is very important. Many methods and technologies have been applied. The result of demarcation is not optimum yet. Using RTK Multi GNSS as in this study is promising. We found improvement in positioning result of even area of limited satellite visibilities and it is match with the forest boundary position requirements.

Further studies are still necessary off course to answer longer baseline, accuracy versus precision, and also combination method like with CORS, RTPPP and event with Total Station, etc. 


\section{Acknowledgements}

Many thanks and appreciation to students and surveyors from Institute of Technology Bandung who helped the investigation in the field, and especially to the vendor PT Wisesa Berkah Bumi for kindly borrowed the STONEX Multi GNSS Receiver so we can measure in the fields.

\section{References}

1. Seeber, G., Satellite Geodesy: foundation, method, and applications, Walter de Gruyter, Berlin-New York, C7 (1993)

2. Abidin, H.Z., Penentuan Posisi dengan GPS dan Aplikasinya (PT. Pradnya Paramita, Jakarta, 1999)

3. Abidin, H.Z., Geodesi Satelit (Departemen Teknik Geodesi ITB, PT. Pradnya Paramita, Jakarta, 2001)

4. Leick A. GPS satellite surveying, 3rd edn Wiley, New York (2004)

5. Hofmann-Wellenhof, B., Lichtenegger, H. and Walse, E., GNSS Global Navigation Satellite Systems: GPS, GLONASS, Galileo, and More. (Springer Verlag, Wien, 2007)

6. Mudita, I.,GNSS-RTK Network Technology Impact Assessment for Land Surveying at Badan Pertanahan Nasional Republik Indonesia (BPN RI): Asian Geospatial Forum: 10 ${ }^{\text {th }}$ Annual Asian Conference \& Exhibition on Geospatial Information, Technology \& Applications (2011) 